\title{
THE EFFECTS OF CRUDE AQUEOUS AND ALCOHOL EXTRACTS OF ALOE VERA ON GROWTH AND ABDOMINAL VISCERA OF SUCKLING RATS
}

\author{
Wabeya Beya $^{a}$, Bruce Davidson ${ }^{\mathrm{a}, \mathrm{b}}$, Kennedy H. Erlwanger ${ }^{\mathrm{a}}$ \\ ${ }^{a}$ School of Physiology, Faculty of Health Sciences, University of the Witwatersrand, 7 York Rd, \\ Parktown 2193, South Africa; ${ }^{b}$ Saint James School of Medicine, Plaza Juliana 4, Kralendijk, Bonaire, \\ Dutch Caribbean. \\ *Email: Kennedy.Erlwanger@wits.ac.za
}

\begin{abstract}
The gastrointestinal tract of neonates is sensitive to dietary manipulations. When nursing mothers use Aloe vera, their babies are at risk of indirect exposure to Aloe vera via breast feeding or directly as health supplements. The effects of orally administered extracts of Aloe vera in unweaned rats were investigated. Six day old Sprague-Dawley rats were gavaged with aqueous or alcohol extracts of Aloe vera (low dose $50 \mathrm{mg} . \mathrm{kg}^{-1}$ or high dose $500 \mathrm{mg}^{\mathrm{kg}} \mathrm{kg}^{-1}$ ) daily for eight days. All data were expressed as mean \pm SD and analyzed by one way ANOVA. Pups receiving high doses of either extract had a significantly higher body mass gain than the group receiving lower dose $(\mathrm{p}<0.05)$. Tibial length was significantly increased in the high dose aqueous extract group (15-26\%). The differences in growth could not be attributed to circulating insulin-like growth factor- 1 as the levels were not significantly different. The caecum was significantly enlarged in the rats that received the high doses of both extracts. Although, there was no significant difference in the non-fasting plasma concentration of glucose and triglycerides, the hepatic lipid and glycogen content were significantly higher $(p<0.001)$ for the high dose aqueous extract group. The plasma alanine transaminase was not affected by the treatments, however the high doses of the extracts significantly increased plasma alkaline phosphatase activity. Short term administration of Aloe vera extracts resulted in growth promotion, enhanced hepatic storage of metabolic substrates, increased ALP possibly in relation to bone growth and caused hypertrophy of the caecum of neonatal rats. These effects need to be explored further to enhance animal production and health.
\end{abstract}

Key words: Aloe vera, neonate, growth, gastrointestinal tract; metabolism

\section{Introduction}

Many plants are exploited as pharmacological agents, despite not being scientifically tested. Aloe vera has many reported biological effects and is well adapted to growth in arid and semi arid regions (Paez and Alejandra, 2000). Most of the biologically active constituents of Aloe vera are found in the leaves (Ramachandra and Srinivasa Rao, 2008). The constituents of Aloe vera include salicylates, phytosterols, $\gamma$-linolenic acid, anthraquinones and resins (Esua and Rauwald, 2006). Aloe vera also contains mucopolysaccharides (Hart et al., 2009) some of which can be absorbed intact from the gastrointestinal tract into the bloodstream where they exert biological effects, such as immunoregulation. Aloe vera extracts have anti-hyperglycaemic effects and may be useful in treating type I and Type II diabetes mellitus by reducing the levels of fasting blood sugar and glycated hemoglobin (Ajabnoor, 1990; Tanaka and Matsuda, 2006) as well as increasing plasma insulin levels (Can et al., 2004). The antidiabetic effect of Aloe vera is thought to be mediated in part by mannans and anthraquinones (Reynolds and Dweck, 1999; Can et al., 2004).

Other chemicals in Aloe vera extracts such as lectins, arginine and $\beta$-carotene are anti-tumor agents and immune modulators (Amusan et al., 2002), but recently Aloe vera products were shown to cause a greater risk for colonic carcinogenicity (Yokohira, et al., 2009). Aloe vera decreases gastric acid secretion and confers gastro-protection from hydrochloric acid injury (Yusuf et al., 2004). Aloe vera may also have a therapeutic effect on inflammatory bowel disease (Langmead et al., 2004).

The expense of conventional medications results in the exploitation of medicinal plants which are readily available in those communities. Herbal medicines administered per os come into direct contact with the gastrointestinal tract (GIT). The GIT is a major source of peptides that regulate metabolism and function (Sorensen, 2009). Dietary manipulations during the suckling period might have long lasting and possibly irreversible effects on some transport mechanisms in the GIT (Pacha, 2000). Some plants/extracts have been shown to cause precocious maturation of the GIT (Linderoth et al., 2006). Given its many biologically active compounds, Aloe vera and its metabolites may have trophic effects and modulate tissue function and structure. Neonatal exposure to Aloe vera may be either directly via extracts used medicinally for constipation and skin problems or via the mother's milk. Thus it is important to study the effects of Aloe vera on the GIT of neonates. 
Beya et al., Afr J Tradit Complement Altern Med. (2012) 9(4):553-560

Publisher: African Networks on Ethnomedicines

Web page: /http://journals.sfu.ca/africanem/index.php/ajtcam/index

http://dx.doi.org/10.4314/ajtcam.v9i4.13

\section{Materials and methods}

This study was performed according to international, national and institutional rules considering animal experiments, clinical studies and biodiversity rights. The study was approved by the Animal Ethics Screening Committee of the University of Witwatersrand (clearance number 2008/37/03).

\section{Plant material}

Fresh Aloe vera plants were sourced from a commercial plant nursery, Flora Farm, Boksburg, South Africa. The University of the Witwatersrand Herbarium verified the identity of the Aloe vera plants and a sample is stored with voucher name Beya 1.

\section{Preparation of aqueous and alcohol extracts of Aloe vera}

The aqueous and alcohol (ethanol) extracts were prepared from fresh Aloe vera leaves. Briefly, $370 \mathrm{~g}$ of freshly cut leaves of Aloe vera were mixed with either $100 \mathrm{ml}$ of $70 \%$ ethanol or $100 \mathrm{ml}$ of distilled water and crushed in a blender, agitated on a shaker incubator for 12 hours, filtered through filter paper (Albert ${ }^{\circ}$, Pore 7-11, size185mm, England) and then lyophilized in a lyophiliser (Vacuum Gauge, USA). The yield for alcohol extract was $1.5 \%$ and for aqueous extracts it was $1.2 \%$. The extracts were stored in tightly sealed dark containers in a freezer at $-20^{\circ} \mathrm{C}$ for later use. Dry matter of the Aloe vera was determined by dessication of the leaf at $50^{\circ} \mathrm{C}$ for 7 days. The moisture content of the Aloe vera was $92 \%$.

\section{Animals and experimental protocols}

Seven adult Sprague Dawley female rats that had given birth to a total of 77 suckling pups (38 males and 39 females) were used in the study. Each dam was housed separately with its respective pups, the treatments were initiated 6 days postpartum whilst the pups remained with their respective dams though out the study period. The littermate pups were randomly allocated to five treatment groups (group I: served as a control and was given distilled water, group II + III were given low $\left(50 \mathrm{mg} \cdot \mathrm{kg}^{-1}\right)$ and high dose $\left(500 \mathrm{mg} \cdot \mathrm{kg}^{-1}\right)$ respectively of Alcoholic extracts of Aloe vera and group IV $+\mathrm{V}$ received low $\left(50 \mathrm{mg} \cdot \mathrm{kg}^{-1}\right)$ and high doses $\left(500 \mathrm{mg} \cdot \mathrm{kg}^{-1}\right)$ of Aqueous extracts of Aloe vera daily respectively. All solutions were administered at $10 \mathrm{ml} . \mathrm{kg}^{-1}$ body mass by gavage via an orogastric tube. The treatments were administered every morning between 09h00-10h00.

\section{Tissue collection and analyses}

After 8 days of treatment, the pups were anaesthetised with sodium pentobarbitone $\left(50 \mathrm{mg} \cdot \mathrm{kg}^{-1}\right)$ to draw blood by cardiac puncture and then subsequently killed with sodium pentobarbitone (150mg. $\mathrm{kg}^{-1}$ EUTHANASE ${ }^{\circ}$, Centaur Labs, Johannesburg, South Africa) injected intraperitoneally. Blood samples were obtained by cardiac puncture using $21 \mathrm{G}$ needles on $1 \mathrm{ml}$ syringes flushed with heparin (Heparin Novo®, Novo Nordisk Company, Johannesburg, South Africa). The blood samples were used immediately for determination of glucose, triglycerides, and liver enzymes. The samples were transferred to plain blood tubes (Greiner Bio-one $\mathrm{GnebH}$, Austria) and then centrifuged at $3000 \mathrm{G}$ at $4^{\circ} \mathrm{C}$ (SorvallRT®6000B) for $15 \mathrm{~min}$ and the plasma was decanted and stored at $-70^{\circ} \mathrm{C}$ until hormonal assays were performed.

\section{Metabolic substrates in blood, liver enzyme activity and IGF-1}

The blood glucose and triglyceride concentrations were determined by use of a glucometer (GLUCOMETER ELITE ${ }^{\circledR}$ 3947, Bayer Company, Japan) and triglyceride meter (ACCUTREND TRIGLYCERIDES, Roche Company, Mannheim, Germany). Liver enzyme activities were determined using a calibrated Reflotron machine (REFLOTRON ${ }^{\circledR}$, Roche diagnostics LTD, Burgess Hill West Sussex, United Kingdom). The hormone IGF-1 was determined by enzyme linked immunosorbent assay (ELISA) using a Mouse IGF-1 kit per manufacturer's instruction (QUANTIKINE ${ }^{\circledR}$, Mouse IGFI, R\&D SystemsEurope). The kit also recognises rat IGF-1 which shares $99 \%$ amino acid sequence identity with mouse IGF1 and the kit has been validated for the determination of rat IGF-I. The sample values were read on a plate reader machine (Multiskan Ascent, Lab system, model no 354, Helsinki, Finland) at 450nm with a second correction wavelength measurement at $540 \mathrm{~nm}$.

\section{Morphology and morphometry of viscera}

After euthanasia, all viscera were removed and weighed. The intestines were stretched out on a board for gross and macroscopic measurements. The intestines were emptied by gentle pressure along their length except for the segment to be used for histology which was removed, flushed with saline and then its mass added to the rest of the intestinal tract. Lengths of the large and small intestines were measured and the mass of the accessory and abdominal organs were determined. After weighing, the livers were frozen at $-20^{\circ} \mathrm{C}$ for later analysis of lipid and glycogen content. Samples of the intestine, liver and caecum were collected for histological evaluation. $1 \mathrm{~cm}$ sections of the small intestine (from the proximal and distal halves) were collected, together with sections of the liver, preserved in $10 \%$ phosphate buffered formalin and then embedded in paraffin. They were then sectioned at $7 \mu \mathrm{m}$ thick and stained with haematoxylin and eosin. The first five serial sections were discarded and then four serial sections with five discarded in between from each segment were used for microscopic 
Publisher: African Networks on Ethnomedicines

Web page: /http://journals.sfu.ca/africanem/index.php/ajtcam/index

http://dx.doi.org/10.4314/ajtcam.v9i4.13

measurements. In both the proximal and distal small intestine villus heights and crypt depth were measured. Similar measurements were made of the caecum samples under light microscopy at $40 \mathrm{x}$ magnification.

\section{Liver glycogen and lipid content}

Standard procedures were used for lipid extraction (Bligh and Dyer, 1959). Briefly, 0.5g of the frozen liver samples were thawed, finely chopped with a scapel blade and then mixed in $100 \mathrm{ml}$ of chloroform - methanol mixture (2:1) and left to extract overnight at $4^{\circ} \mathrm{C}$. The samples were then filtered through filter paper (Albert ${ }^{\circledR}$, Pore $7-11$, Size $185 \mathrm{~mm}$ ), $30 \mathrm{ml} 0.9 \%$ saline added, mixed, and allowed to stand overnight at $4^{\circ} \mathrm{C}$. The bottom (chloroform) phase was collected and reduced to dryness under vacuum at $37^{\circ} \mathrm{C}$ and redissolved in $20 \mathrm{ml}$ chloroform. $2 \mathrm{ml}$ aliquots were each placed in a dried, pre-weighed vial, and re-dried at $50^{\circ} \mathrm{C}$ for 30 minutes, cooled and then reweighed to determine the lipid content. The residual liver samples (post lipid extraction) were also dried and their dry matter content determined. The glycogen content of the liver was determined indirectly (Passonneau and Lauderdale, 1974). Briefly, 0.1g of the liver was placed in $1 \mathrm{ml}$ of $0.03 \mathrm{M}$ hydrochloric acid and homogenised with an ultra turrex homogeniser for 20 seconds. To hydrolyse the glycogen, $1 \mathrm{ml}$ of $1 \mathrm{M}$ hydrochloric acid was added to the homogenate and the mixture placed in sealed tubes in a boiling water bath for 2 hours. One $\mathrm{ml}$ of $1 \mathrm{M}$ sodium hydroxide was added to neutralise the acid. Glucose content of the solution was determined via a glucose assay kit (Sigma catalogue, GAGO-20) and the glycogen expressed as glucose equivalents (mmol.g $\left.{ }^{-1}\right)$.

\section{Tibia and femur length and mass}

The right femoral head was carefully removed from the acetabulum, the muscles and soft tissues removed from the bones (tibia and femur) and the length of the bones measured using a thread and ruler. The bones were dried at $50^{\circ} \mathrm{C}$ for 7 days and weighed until their dry mass was constant. Acute toxicity studies were not performed however oral doses of alcohol extracts up to $16 \mathrm{~g} / \mathrm{kg}$ body weight for 6 weeks have been shown to be non toxic to adult rats (Saritha and Anilakumar, 2010).

\section{Statistical analyses}

All data were expressed as mean $\pm \mathrm{SD}$. A one way analysis of variance (ANOVA) was used to assess the effects of Aloe vera extracts on the parameters measured between groups followed by a Bonferroni post hoc test. The level of significance was set at $\mathrm{p}<0.05$. All the statistical analyses were performed using Graph Pad Prism version 5.0 (Graph Pad, San Diego, C.A).

\section{Results}

All animals remained healthy during the study and no incidental or iatrogenic mortalities were recorded. There was no significant difference in the initial mass of the suckling rats after allocation to different groups (Table 1). After 8 days on the various treatments, all groups body mass increased significantly compared to initial (Table 1 and Figure 1), but with significantly increased final body masses compared to controls seen with the high doses of the aqueous $(\mathrm{p}<0.05)$ and alcohol $(\mathrm{p}<0.001)$ Aloe vera extracts.

A significant increase was observed ( $\mathrm{p}<0.05$, ANOVA) in the absolute mass of the caecum of suckling rats fed with high doses of the alcohol $(\mathrm{AlcH})$ and the aqueous $(\mathrm{AqH})$ extracts of Aloe vera (Table 1) compared to the control group. When considering individually all of the other organs as a percentage of body mass (relative to body mass), there were no significant differences observed ( $p>0.05$, ANOVA) between the groups, except for the relative mass of the caecum which was increased. Histologically, the caeca of the rats on the high doses of the aqueous and alcohol extracts had significantly increased thickness of the muscularis, submucosa and mucosa layers (Table 2).

There was no significant difference in linear growth of the femur (Table 3) amongst the different treatment groups $(\mathrm{p}>0.05)$, however, the rats fed with AqH had significantly $(\mathrm{p}<0.05)$ longer tibias than the controls, but there was no difference observed in the tibial masses of the bones from the different treatment groups.

Supplementation with Aloe vera extracts had no significant effect on the small intestinal villus height and crypt depth (data not shown). Liver histology was similar between treated and controls (not shown).

The content of lipids and glycogen in the liver was significantly increased in the suckling rats given the AqH of Aloe vera $(\mathrm{p}<0.001)$. For the different groups of rats, there was no significant difference in the plasma concentrations of metabolic substrates (glucose and triglycerides) and, IGF-I however the Alkaline phosphatase was significantly elevated $(\mathrm{P}<0.05)$ in the pups administered the AlcH (Table 4).

\section{Discussion}

The rate of growth and development of rat pups can be greatly altered by varying supplements administered to them during the suckling period (Swanson et al., 1984). Our results indicate that oral Aloe vera extracts administered as a dietary supplement to suckling rats positively influenced the growth performance, as well as the caecum. 


\section{Effect of Aloe vera extracts on body mass gain}

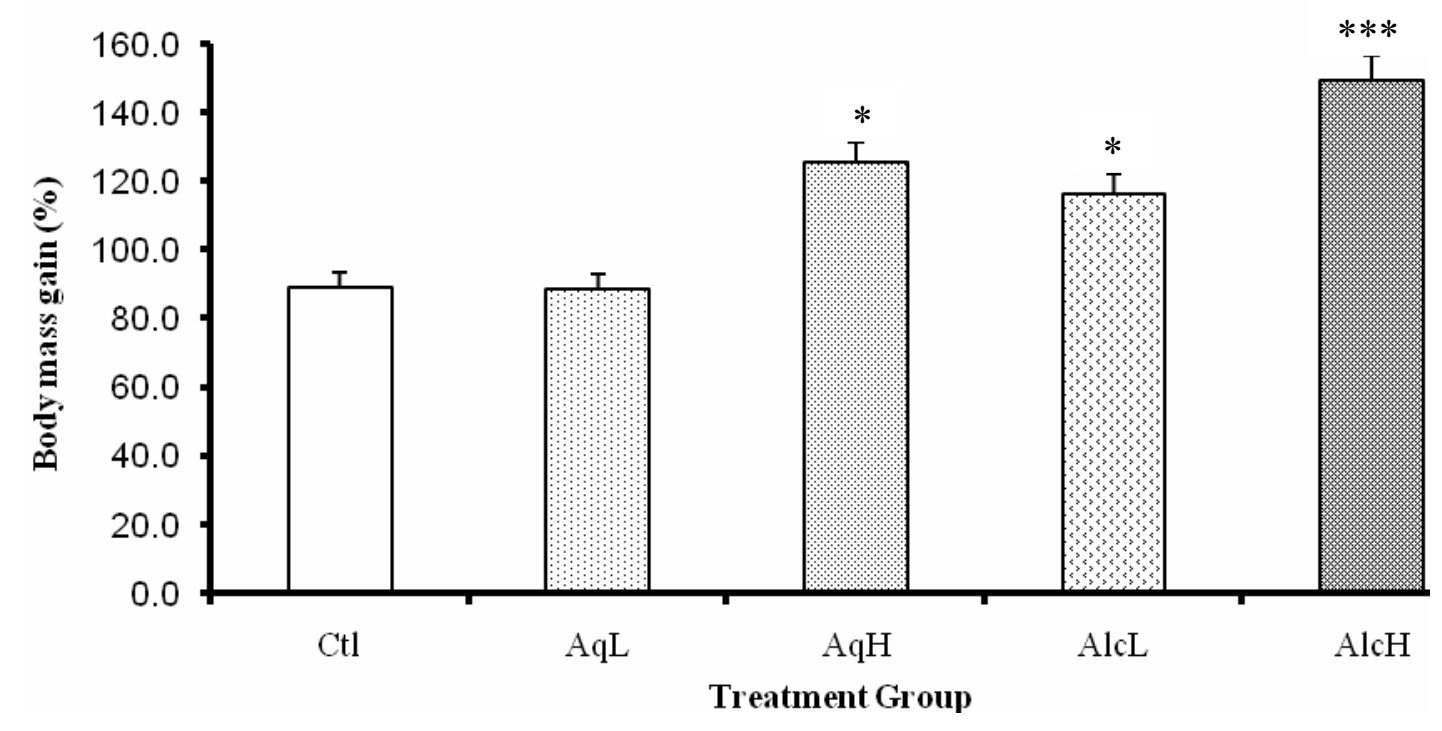

Figure 1: Effect of Aloe vera extracts on the body mass gain (\%) of suckling rats after 8 days of treatment (mean $\pm \mathrm{SD})$. ${ }^{*} \mathrm{p}<0.05$ for aqueous high $(\mathrm{AqH})$ and Alcohol low (AlcL) vs control (Ctl) and vs aqueous low (AqL). $* * * \mathrm{p}<0.001$ alcohol high $(\mathrm{AlcH})$ vs. all groups.

Table 1: Effect of Aloe vera extracts on the body mass, absolute $(\mathrm{g})$ and relative mass (\% body mass) and, length ( $\mathrm{cm})$ of viscera of suckling rats.

\begin{tabular}{lccccc}
\hline & $\begin{array}{c}\mathrm{Ctl} \\
(\mathrm{n}=11)\end{array}$ & $\begin{array}{c}\mathrm{AqL} \\
(\mathrm{n}=12)\end{array}$ & $\begin{array}{l}\mathrm{AqH} \\
(\mathrm{n}=12)\end{array}$ & $\begin{array}{c}\text { AlcL } \\
(\mathrm{n}=12)\end{array}$ & $\begin{array}{c}\text { AlcH } \\
(\mathrm{n}=12)\end{array}$ \\
\hline Initial BM(g) & $16 \pm 1.50$ & $16.33 \pm 1.19$ & $16.46 \pm 1.51$ & $14.63 \pm 1.77$ & $16.33 \pm 1.9$ \\
End BM(g) & $30.09 \pm 2.30$ & $30.75 \pm 2.67$ & $37.75 \pm 3.71^{*}$ & $31.21 \pm 3.11$ & $40.25 \pm 1.97^{*}$ \\
S.I (cm) & $502.50 \pm 57.01$ & $526.67 \pm 60.55$ & $542.00 \pm 128.82$ & $513.33 \pm 23.38$ & $517.50 \pm 36.96$ \\
Absolute S.I (g) & $0.03 \pm 0.00$ & $0.03 \pm 0.00$ & $0.03 \pm 0.00$ & $0.03 \pm 0.00$ & $0.03 \pm 0.00$ \\
Relative S.I (\%) & $0.09 \pm 0.00$ & $0.09 \pm 0.00$ & $0.07 \pm 0.00$ & $0.09 \pm 0.00$ & $0.07 \pm 0.00$ \\
L.I (cm) & $74.67 \pm 6.87$ & $73.57 \pm 8.52$ & $76.67 \pm 13.29$ & $75.71 \pm 11.70$ & $75.00 \pm 10.22$ \\
Absolute L.I (g) & $0.14 \pm 0.06$ & $0.12 \pm 0.02$ & $0.13 \pm 0.03$ & $0.11 \pm 0.04$ & $0.12 \pm 0.03$ \\
Relative L.I (\%) & $0.46 \pm 0.09$ & $0.39 \pm 0.05$ & $0.34 \pm 0.06$ & $0.35 \pm 0.07$ & $0.29 \pm 0.05$ \\
Caecum (g) & $0.07 \pm 0.01$ & $0.08 \pm 0.03$ & $0.10 \pm 0.06^{* * *}$ & $0.08 \pm 0.03$ & $0.96 \pm 0.08^{* * *}$ \\
Liver (g) & $0.87 \pm 0.13$ & $0.87 \pm 0.11$ & $1.20 \pm 0.30$ & $0.99 \pm 0.10$ & $1.27 \pm 0.22$ \\
Liver (\%) & $2.91 \pm 0.52$ & $2.83 \pm 0.33$ & $3.25 \pm 0.63$ & $3.16 \pm 0.24$ & $3.15 \pm 0.51$ \\
Stomach (g) & $0.21 \pm 0.06$ & $0.22 \pm 0.06$ & $0.22 \pm 0.44$ & $0.19 \pm 0.03$ & $0.21 \pm 0.04$ \\
Stomach (\%) & $0.69 \pm 0.17$ & $0.70 \pm 0.18$ & $0.59 \pm 0.12$ & $0.61 \pm 0.12$ & $0.53 \pm 0.09$ \\
Spleen (g) & $0.15 \pm 0.03$ & $0.17 \pm 0.03$ & $0.18 \pm 0.03$ & $0.16 \pm 0.02$ & $0.16 \pm 0.03$ \\
Spleen (\%) & $0.51 \pm 0.12$ & $0.54 \pm 0.12$ & $0.48 \pm 0.09$ & $0.51 \pm 0.08$ & $0.40 \pm 0.08$ \\
\hline
\end{tabular}

For data in any row, indicated significant differences $\left({ }^{*} \mathrm{p}<0.05\right.$ and $\left.* * * \mathrm{p}<0.001\right)$ are relative to control. $\mathrm{BM}=$ body mass; $\mathrm{LI}=$ large intestine; $\mathrm{SI}=$ small intestine, $\mathrm{Ctl}$ : Control, AqL: aqueous low, AqH: aqueous high, AlcL: alcohol low, AlcH: alchol high. 
Publisher: African Networks on Ethnomedicines

Web page: /http://journals.sfu.ca/africanem/index.php/ajtcam/index

http://dx.doi.org/10.4314/ajtcam.v9i4.13

Table 2: Effect of orally administered Aloe vera extracts on the morphometry of the caecum of suckling rats (mean \pm SD) after 8 days of treatment

\begin{tabular}{llcccc}
\hline & Ctl & AqL & AqH & AlcL & AlcH \\
\hline Serosa & $1.40 \pm 0.21$ & $2.04 \pm 0.43$ & $5.01 \pm 0.83^{*}$ & $1.58 \pm 0.23$ & $2.06 \pm 0.20$ \\
Muscularis & $8.26 \pm 0.65$ & $8.26 \pm 0.81$ & $35.6 \pm 7.19^{* *}$ & $8.06 \pm 1.07$ & $20.76 \pm 0.81^{*}$ \\
Submucosa & $8.48 \pm 0.87$ & $13.5 \pm 4.02$ & $9.8 \pm 6.61$ & $12.82 \pm 3.60$ & $12.12 \pm 3.23$ \\
$\begin{array}{l}\text { Mucosa } \\
\text { Epithelium }\end{array}$ & $2.80 \pm 0.52$ & $3.62 \pm 0.48$ & $3.76 \pm 0.51$ & $3.96 \pm 0.40$ & $3.59 \pm 0.25$ \\
Total thickness & $20.94 \pm 2.25$ & $30.72 \pm 5.74$ & $67.16 \pm 15.14^{* * *}$ & $30.42 \pm 5.30$ & $41.93 \pm 4.49^{* * *}$ \\
\hline
\end{tabular}

Data in the same row with different superscripts indicate significant difference $\left(* * * p<0.001,{ }^{* *} p<0.01,{ }^{*} p<0.05\right)$ between control group and treatments groups.

Table 3: Effect of Aloe vera on the absolute and relative length and mass of the tibias and femurs of the rats

\begin{tabular}{lccccc}
\hline & Ctl & AqL & AqH & AlcL & AlcH \\
\hline $\begin{array}{l}\text { Tibia } \\
\text { Length (mm) }\end{array}$ & $15.00 \pm 0.89$ & $15.66 \pm 1.07$ & $18.91 \pm 1.31^{* * *}$ & $16.75 \pm 0.96$ & $16.75 \pm 1.05$ \\
Mass (mg) & $4.10 \pm 0.07$ & $4.20 \pm 0.07$ & $4.60 \pm 0.06$ & $4.20 \pm 0.09$ & $4.20 \pm 0.06$ \\
Femur & & & & & \\
Length (mm) & $12.09 \pm 0.94$ & $12.25 \pm 0.86$ & $13.5 \pm 0.52$ & $12.33 \pm 0.65$ & $12.91 \pm 0.79$ \\
Mass (mg) & $4.30 \pm 0.10$ & $4.20 \pm 0.50$ & $4.00 \pm 0.10$ & $4.20 \pm 0.70$ & $4.00 \pm 0.60$ \\
& & & & &
\end{tabular}

The rats administered the high dose of aqueous extracts for 8 days had significantly longer tibias $(* * * p<0.001)$ compared to the control group.

Table 4. Effect of Aloe vera extracts on non fasting blood concentrations of glucose, triglycerides, ALT, ALP, IGF-1 and hepatic glycogen and lipid content of suckling rats after 8 days of treatment

\begin{tabular}{|c|c|c|c|c|c|}
\hline & $\mathrm{Ctl}$ & $\mathrm{AqL}$ & $\mathrm{AqH}$ & AlcL & $\mathrm{AlcH}$ \\
\hline \multicolumn{6}{|l|}{ Blood/plasma } \\
\hline NF Glucose $\left(\mathrm{mmol}^{-1} \mathrm{l}^{-1}\right)$ & $4.3 \pm 1.2$ & $5.93 \pm 0.8$ & $6.0 \pm 0.5$ & $5.3 \pm 1.5$ & $5.9 \pm 0.5$ \\
\hline NF TG $\left(\mathrm{mmol} .1^{-1}\right)$ & $4.3 \pm 1.2$ & $3.7 \pm 0.5$ & $3.8 \pm 1.3$ & $4.3 \pm 1.0$ & $4.4 \pm 1.7$ \\
\hline $\begin{array}{l}\text { Mouse IGF-I equivalent } \\
\left(\mathrm{Pg} . \mathrm{ml}^{-1}\right)\end{array}$ & $140.5 \pm 40$ & $141.4 \pm 25$ & $118.6 \pm 34$ & $103.3 \pm 13$ & $151.8 \pm 44$ \\
\hline $\operatorname{ALT}\left(\mathrm{U}^{\prime} 1^{-1}.\right)$ & $9.5 \pm 5.8$ & $11.9 \pm 6.9$ & $10.7 \pm 8.1$ & $11.9 \pm 7.9$ & $10.3 \pm 5.5$ \\
\hline $\operatorname{ALP}\left(\mathrm{U}^{-1} \mathrm{1}^{-1}\right)$ & $357 \pm 16$ & $355 \pm 64$ & $432 \pm 13$ & $413 \pm 12$ & $474 \pm 14^{* * *}$ \\
\hline \multicolumn{6}{|l|}{ Liver } \\
\hline Lipid content $\left(\mathrm{mg} \mathrm{g}^{-1}\right)$ & $40 \pm 10$ & $26 \pm 8$ & $78 \pm 14 * * *$ & $34 \pm 9$ & $47 \pm 11$ \\
\hline Glycogen $\left(\mathrm{mmol}^{-1}\right)$ & $1.9 \pm 0.4$ & $2.3 \pm 0.5$ & $3.5 \pm 0.5 *$ & $1.8 \pm 0.4$ & $2.2 \pm 0.4$ \\
\hline
\end{tabular}

Control group administered distilled water (Ctl), Aqueous low dose (AqL), Aqueous high dose (AqH), Alcohol low dose (AqL), Alcohol high dose (AlcH), NF TG: Non fasting triglycerides, IGF-1: insulin- like growth factor-1, ALT: alanine aminotransaminase, ALP: alkaline phosphatase. indicates significant difference $(\mathrm{p}<0.05)$ compared to all other groups, $* * *$ indicates significant difference $(\mathrm{p}<0.001)$ compared to all other groups. 
Publisher: African Networks on Ethnomedicines

Web page: /http://journals.sfu.ca/africanem/index.php/ajtcam/index

http://dx.doi.org/10.4314/ajtcam.v9i4.13

Tibial length has been used as a more accurate indicator of linear growth compared to body mass gain, which can be influenced by several factors including food intake and hydration status (Eshet et al., 2004). Growth hormone (GH) is a key hormone for promotion of growth and development (Tisi et al., 2005). GH mediates its growth promoting effects directly by stimulating protein deposition in the body and bone and visceral growth (Tisi et al., 2005) and indirectly via stimulation of production of the somatomedins IGF-I and IGF-II. The indirect GH action via IGF-1 is thought to be the major mechanism for its effects (Baroncelli et al., 2003). However, despite the increased tibial length of the AqH rats, our results did not show any significant differences in IGF-1 suggesting either a direct growth promoting effect of the extracts or a mechanism mediated by other endogenous factors/hormones which we did not investigate.

Nutrients play crucial roles in the development, adaptation and functioning of the GIT. Assessment of morphological changes can be used in the diagnosis and assessment of intestinal pathology (Isukura et al., 1992). In this study, no significant changes occurred in the gross morphometry and histology of the small and large intestines, other than in the caecum. Dietary manipulations rapidly manifest in GIT morphological changes (Pacha, 2000), thus any effects of Aloe vera on the small intestine should have been visible. However, its absorptive and secretory capacity was not tested. It is thus possible that function, but not morphology, may have been affected. The caecal mass was significantly increased by hypertrophic and hyperplastic changes in the rats exposed to Aloe vera. In a previous study where suckling rats were administered extracts from the African potato (Hypoxis hemerocallidea) an increased caecal mass was also the only morphological change noted (Erlwanger and Cooper, 2008). Dietary manipulation and the presence of osmotically active or fermentable substances may affect the GIT flora and influence caecum weight (Baltrop and Brueton, 1990). The increased caecal mass could have been due to the presence of complex carbohydrates in the Aloe extracts resulting in the development of the caecal microflora (Reddy, 1971). However, the role of growth factors in cell proliferation and in cell migration (Podolsky, 1993; Dignass and Lynch-Devaney, 1995) should not be overlooked as an explanation for the increased caecal mass.

The liver is the primary detoxification and metabolic centre in the body and is prone to damage as a consequence of exposure to toxins (Gaskill et al., 2004). Alkaline phosphatase (ALP) and alanine transaminase (ALT) are important markers of liver damage hence their plasma concentrations were used to assess the hepatotoxicity of the Aloe vera extracts. No significant differences in ALT were detected. Indeed, previous studies have showed that Aloe-emodin a constituent of Aloe vera could be hepato-protective in rats exposed to emodin (Woo et al., 2002). The ALP levels were significantly elevated in the rats exposed to the high dose of alcoholic extracts of Aloe vera. Although circulating ALP elevations are usually associated with bile duct damage/bile stasis, ALP is also released from bone following pathology or excessive remodelling as during rapid growth as in this study.

The liver plays an important role in metabolism to maintain energy levels. The blood concentration of glucose in young rats is maintained at a fairly constant level from 2 to 20 days after birth (Innis, 1985). The glucose level in non fasting blood after 8 days of treatment with Aloe vera extracts did not show any significant differences between the groups. This suggests that the Aloe vera extracts did not affect endocrine pancreatic function. Fatty acids will accumulate in the liver unless the rate of export in plasma lipoproteins or oxidation $\mathrm{CO}_{2}$ is increased (Erol et al., 2004). Fatty liver is a metabolic disorder that occurs when the rate of fatty acid uptake and esterification exceeds the rate of fatty acid depletion either through oxidation or export as very low density lipoproteins. The rats exposed to the high dose of alcoholic Aloe vera extracts showed the greatest accumulation of lipids in the liver, however the lipids were not profiled so the metabolic processes underlying the increased accumulation could not be fully ascertained.

This study concurs with findings from other studies which revealed the beneficial effects of Aloe vera extracts administration over a short period of time. There is however a need to explore further the mechanisms of improved growth performance and the significance of the changes in caecal morphology noted as a result of exposure of the suckling rats to the Aloe vera extracts.

\section{Conclusion}

Herbal medicines are widely used in almost all sectors of the population. Aloe vera extracts administered orally to suckling rats have a positive effect on body mass, caecum and tibial bones in the short term. These effects could be useful in preventing weight loss during weaning and bone disturbances during development of fast growing animals. Longer time period studies to determine the reversibility and functional significance of the effects should be undertaken, as well as broadening the range of parameters assessed. If similar increases in body mass occur in other species then Aloe vera could be used commercially in animal production to improve growth in farm animals. This study involved the use of crude extracts; future studies should be undertaken to identify the specific chemical components of Aloe vera which induced the significant differences shown.

\section{Acknowledgements}

The authors are indebted to Miss Margaret Badenhorst for her invaluable technical support in performing the hormonal assays, preparation and processing of the slides for histology and preparation of reagents. Mr Eliton Chivandi, Dr. Oluwafolajini and Trevor Nyakudya are also thanked for their assistance with the Statistics done during this research. The study was supported financially by the National Research Foundation, the University of the Witwatersrand, Faculty of Health Sciences Research Committee grants and, the School of Physiology, South Africa. 
Publisher: African Networks on Ethnomedicines

Web page: /http://journals.sfu.ca/africanem/index.php/ajtcam/index

http://dx.doi.org/10.4314/ajtcam.v9i4.13

\section{References}

1. Ajabnoor M. A. (1990). Effect of Aloes on the blood glucose levels in normal and alloxan diabetic mice. J. Ethnopharmacol., 28: 215-220.

2. Amusan, O. O. G., Dlamini, P. S., Msonthi, J. D. and Makhubu, L. P. (2002). Some herbal remedies from Manzini region, Swaziland. J. Ethnopharmacol., 79: 109-112.

3. Baltrop, D. and Brueton, T. M. (1990). The gastrointestinal tract and short term toxicity tests. In: P. J., Bordeau, Editor, Short-term Toxicity Tests for non-genotoxic Effects, John Wiley and Sons Ltd 99-110.

4. Baroncelli, G. I., Bertelloni, S., Sodini, F. and Saggese, G. (2003). Acquisition of bone mass in normal individuals and in patients with growth hormone deficiency. J. Pediatr. Endocrinol. Metab., 16: 327-335.

5. Bligh, E. G. and Dyer, W. J. (1959). A rapid method of total lipid extraction and purification. Can. J. Biochem. Physiol., 37: 911-917.

6. Can, A., Akev, N., Ozsoy, N., Bolkent, S., Arda, B. P., Yanardag, R. and Okyar, A. (2004). Effect of Aloe vera leaf gel and pulp extracts on the liver in type-II diabetic rat models. Biol. Pharmacol. Bull., 27: 694-698.

7. Dignass, A. V., and Lynch-Devaney, K. (1995). Hepatocyte growth factor/Scatter factor modulates intestinal epithelial cell proliferation and migration. Biochem. Biophys. Res. Comm., 202: 701-709.

8. Erlwanger, K. H. and Cooper, R. G., (2008). The effects of orally administered crude alcohol and aqueous extracts of African potato (Hypoxis hemerocallidea) corm on the morphometry of viscera of suckling rats. Food Chem. Toxicol., 46: 136-139.

9. Erol, E., Kumar, L. S., Cline G. W., Shulman, G. L., Kelly, D. P. and Binas, B. (2004). Liver fatty acid-binding protein is required for high rates of hepatic fatty acid oxidation but not for the action of PPAR- $\alpha$ in fasting mice. J. Fed. Am. Soc. Exp. Biol., 18: 347-349.

10. Eshet, R., Maor, G., Ari, B. T., Eliezer, B. M., Gatyablonski, G. and Phillip, M. (2004). The aromatase inhibitor letrozole increases epiphyseal growth plate height and tibial length in peripubertal male mice. J. Endocrinol., 182: 165172.

11. Esua, M. F. and Rauwald, J. W. (2006). Novel bioactive maloyl glucans from Aloe vera gel: isolation, structure elucidation and in vitro bioassays. Carbon Resource, 27: 355-364.

12. Gaskill, C. L., Hoffmann, W. E. and Cribb, A. E. (2004). Serum alkaline phosphatase isoenzyme profiles in Phenobarbital-treated epileptic dogs. Vet. Clin. Pathol., 33: 215-222.

13. Hart, L. A., van Enckevort, P. H., van Dijk, H., Zaat, R., de Silva, K. T. and Labadie, R. P. (2009). Two functionally and chemically distinct immunomodulatory compounds in gel of Aloe vera. J. Ethnopharmacol., 23: 61-71.

14. Innis, S. M. (1985). The role of diet during development on the regulation of adult cholesterol homeostasis. Can. J. Physiol. Pharmacol., 63: 557-564.

15. Isukura, M., Evers, M., Parikh, D. (1992) Neurotensin augments intestinal regeneration after small bowel resection in the rat. Annals of Surgery 125,520-5.

16. Langmead, L., Makins, R. J. and Rampton, D. S. (2004). Anti-inflammatory effects of Aloe vera gel in human colorectal mucosa in vitro. Alimen. Pharmacol. Therap., 19: 521-527.

17. Linderoth, A., Prykhod'ko, O., Pierzynowski, S. G. and Weström, B. R. (2006). Enterally but not Parenterally Administered Phaseolus vulgaris Lectin Induces Growth and Precocious Maturation of the Gut in Suckling Rats. Biol. Neonate, 89: 60-68.

18. Pacha, J., (2000). Development of intestinal transport function in mammals, Physiol. Rev., 80: 1633-1667.

19. Paez, A, Gebre, G. M., Gonzalez, M. E. and Tschaplinski, T. J. (2000). Growth, soluble carbohydrate and aloin concentration of Aloe vera plants exposed to three irradiance levels. Environ. Experimental Biol., 44: 133-139.

20. Passonneau, J. V. and Lauderdale, V. R. (1974). A comparison of three methods of glycogen measurement in tissues. Analyt. Biochem., 60: 405-412.

21. Podolsky, D. K. (1993). Regulation of intestinal epithelial proliferation: a few answers, many question. Am. J. Physiol., 264: G179-G186.

22. Ramachandra, C. T. and Srinivasa Rao, P. (2008). Processing of Aloe vera leaf Gel: A review. Am. J. Agric. Biol. Sci., 3: 502- 510 .

23. Reddy, B. S. (1971). Calcium and magnesium absorption: role of intestinal microflora. Fed. Proc., 30: 1815-1821.

24. Reynolds, T. and Dweck, A. C. (1999). Aloe vera leaf gel: a review update. J. Ethnopharmacol., 68: 3-37.

25. Saritha, V. and Anilakumar, K.R. (2010). Toxicological evaluation of methanol extract of Aloe vera in rats. Int. J. Pharmaceut. Biomed. Res., 1: 142-149.

26. Sorensen, A., Mayntz, D., Simpson, S. J. and Raubenheimer, D. (2009). Dietary ration of protein to carbohydrate induces plastic responses in the gastrointestinal tract of mice. J. Physiol., (180): 259-266.

27. Swanson, H. H., Bolwerk, E. and Brenner, E. (1984). Effects of cooling in infant rats on growth, maturation, sleep patterns and responses to food deprivation. Br. J. Nutr., 52: 139-148.

28. Tanaka, M. and Matsuda, M.A. (2006). Identification of five phytosterols from Aloe vera gel as antidiabetic compounds. Biol. Pharmaceutical Bull., 29: 1418-1422.

29. Tisi, D.K., Liu, X.J., Wykes, L.J., Skinner, C.D. and Koski, K.G. (2005). Insulin-Like Growth Factor II and Binding Proteins 1 and 3 from Second Trimester Human Amniotic Fluid Are Associated with Infant Birth Weight. J. Nutr., 135: 1667-1672.

30. Woo, S.W., Nan, J.X., Lee, S.H., Park, E.J., Zhao, Y.Z. and Sohn, D.H. (2002). Aloe-emodin suppresses myofibroblastic differentiation of rat hepatic stellate cells in primary culture. Pharmacol. Toxicol., 90: 193-198. 
Beya et al., Afr J Tradit Complement Altern Med. (2012) 9(4):553-560

Publisher: African Networks on Ethnomedicines

Web page: /http://journals.sfu.ca/africanem/index.php/ajtcam/index

http://dx.doi.org/10.4314/ajtcam.v9i4.13

31. Yokohira, M., Matsuda, Y., Suzuki, S., Hosokawa, K., Yamakawa, K., Hashimoto, N., Saoo, K., Nabae, K., Doi, Y., Kuno, T. and Imaida, K. (2009). Equivocal colonic carcinogenicity of Aloe arborescens Miller var. natalensis berger at high-dose level in a Wistar Hannover rat 2-y study. J. Food Sci., 74: T24-30.

32. Yusuf, S., Agunu, A. and Diana, M. (2004). The effect of Aloe vera A. Berger (Liliaceae) on gastric acid secretion and acute gastric mucosal injury in rats. J. Ethnopharmacol., 93: 33-37. 